\title{
Labor costs for prehistoric earthwork construction: experimental and archaeological insights from the Lower Yangzi Basin, China
}

Post-print/Accepted manuscript

Liye Xie

Steven L. Kuhn

Guoping Sun

John W. Olsen

Yunfei Zheng

Pin Ding

Ye Zhao

Xie, Liye, Steven L. Kuhn, Guoping Sun, John W. Olsen, Yunfei Zheng, Pin Ding, and Ye Zhao 2015 Labor Costs for Prehistoric Earthwork Construction: Experimental and Archaeological Insights from the Lower Yangzi Basin, China. American Antiquity 80:67-88. doi:10.7183/0002-7316.79.4.67

(C) 2015 Society for American Archaeology. Used by permission from American Antiquity, volume 80, number 1.

\section{HOW TO CITE TSPACE ITEMS}

Always cite the published version, so the author(s) will receive recognition through services that track citation counts, e.g. Scopus. If you need to cite the page number of the TSpace version (original manuscript or accepted manuscript) because you cannot access the published version, then cite the TSpace version in addition to the published version using the permanent URI (handle) found on the record page. 


\title{
LABOR COSTS FOR PREHISTORIC EARTHWORK CONSTRUCTION: EXPERIMENTAL AND ARCHAEOLOGICAL INSIGHTS FROM THE LOWER YANGZI BASIN, CHINA
}

\author{
Liye Xie, Steven L. Kuhn, Guoping Sun, John W. Olsen, Yunfei Zheng, Pin Ding, and Ye Zhao
}

\begin{abstract}
This paper examines choices of earth-working tools made by Neolithic Chinese populations. In the Hemudu Culture (70005000 B.P.), bone (scapula) digging tools were used from the earliest times, whereas peoples in surrounding areas used stone spades. A range of experiments on manufacturing costs, durability, and use efficiency under realistic conditions show that bone and stone spades are functionally equivalent when soils are soft, but that stone implements provide significant and easily perceived advantages when working harder soils. The persistence of scapular spades in the Hemudu Culture would have constrained decisions about undertaking large construction projects under normal soil conditions. Our results show that, in addition to generalized labor for construction, labor demands for producing earth-working implements for largescale prehistoric earthworks could have also been substantial. These findings not only help explain the processes of intensifying rice-agriculture and sedentary settlements in the Lower Yangzi Basin, but also create a solid foundation for further investigation of how the recruitment of both generalized and specialized laborers, the organization of craft production, and the relevant logistics for large-scale earthworks may have paralleled concentrations of political power in prehistory.
\end{abstract}

Este artículo examina las elecciones de herramientas de excavación en poblaciones chinas del neolítico. Las herramientas de excavación hechas de hueso (escápula) fueron utilizadas desde los inicios de la cultura Hemudu (7000-5000 A.P), a diferencia de los habitantes de las zonas aledañas, quienes utilizaron palas líticas. Una serie de experimentos sobre costos de manufactura, durabilidad y eficiencia bajo condiciones reales demuestran que las palas líticas y de hueso son funcionalmente equivalentes en condiciones de suelo blando, sin embargo las herramientas líticas proveen importantes y evidentes ventajas en condiciones de suelo más duro. El persistente uso de las palas de escápula en la cultura Hemudu habría limitado decisiones relacionadas con grandes proyectos de construcción bajo condiciones normales de suelo. Nuestros resultados demuestran que, además de la labor de construcción, la demanda de labor de producción de implementos de excavación de gran escala habría sido substancial. Estos resultados no solo ayudan a explicar los procesos de intensificación de la producción de arroz y los asentamientos sedentarios en la cuenca baja de Yangzi, sino también a establecer una base sólida para investigaciones futuras relacionadas con el reclutamiento de obreros especializados y no especializados, con la organización de la producción artesanal y con la logística de trabajos agrícolas de gran escala, que podrían asociarse con concentraciones de poder político en la prehistoria.

$\mathrm{A}$ rchaeologists have speculated about the labor costs and the minimum population sizes and/or levels of labor organization for large agricultural undertakings and for construction and maintenance of large architectural projects (e.g., Atkinson 1961; Fuller and Qin 2009; McAnany 1992). Experiments have been conducted to measure how much time and labor might have been needed to produce different sorts of earthen structures (e.g., Abrams 1984, 1994; Ashbee and Cornwall 1961; Hard et al. 1999; Milner et al. 2010; Evans and Limbrey 1974). Common conclusions are that the labor required to build monuments is less than previously thought or that required labor could have been easily recruited by non-state level polities (Abrams 1987; Abrams and Bolland 1999; Arco and Abrams 2006; Erasmus 1965; Hammerstedt

Liye Xie $\square$ University of Toronto, Mississauga, Ontario L5L1C6, Canada (liye.xie@ utoronto.ca)

Steven L. Kuhn and John W. Olsen - School of Anthropology, The University of Arizona, Tucson, Arizona 85721

Guoping Sun, Yunfei Zheng, Pin Ding, and Ye Zhao $\square$ Zhejiang Provincial Institute of Cultural Relics and Archaeology, 26 Jiashanxincun, Jiashan Road, Hangzhou City, Zhejiang 310014, China 
2005; Milner 1998; Muller 1997; Webster and Kirker 1995). However, past research has overlooked the investment in more specialized labor such as craftspeople who provided technological support for earth-working activities. Moreover, most experimental reports lack quantitative descriptions of soil properties in the experimental fields. Applying experimental results from one area to another without considering differences in soil properties could produce misleading estimates (e.g., Shelach 2013).

The research presented here uses controlled archaeological experiments under realistic conditions to generate comprehensive data for the estimation of labor costs of construction and field tillage in Chinese Neolithic contexts. These results implicate the practicality and feasibility of exploiting areas with different soil conditions. We measured (1) the properties of soil in experimental fields, (2) the time costs of digging, and (3) "costs" in both energy and implements. We were particularly interested in implement consumption because we suspect that it would have been an important consideration in prehistoric construction projects. Even modern digging equipment made of advanced materials engineered for abrasion resistance requires frequent repair and replacement (e.g., Dawson et al. 1982; Gillette 1920). With additional data from the manufacturing costs of experimental earth-working implements, we are able to estimate the work needed for producing implements for different tasks.

This study was conducted in the Lower Yangzi Basin in China, where bone and stone earth-working implements were respectively employed in Hemudu and Majiabang-Songze Cultures (70005000 B.P.). The results are particularly relevant to understanding the relationships between choices of earth-working implements, the scales of land modification in farming and construction, and the constraints on expanding land use into areas with more compact soils. Nonetheless, our results can also be applied to understanding aspects of later Liangzhu Culture (5300-4200 B .P.) in relation to constructing massive earthworks. More generally, the results provide a solid technofunctional basis for understanding and evaluating prehistoric choices in earth-working implements and scales of land modification in different societies.

\section{Cultural Background to the Neolithic Lower Yangzi Basin}

The cultivation of rice (and probably other crops as well) in the lower Yangzi can be traced back to about 11,000 B.P., with the Shangshan culture (Fuller et al. 2007; Liu et al. 2007). In the basin, wide-bladed earth-working implements did not develop until around 7200 B.P. This class of tool first appears in the form of spades crafted from wild water buffalo scapulae (Xie 2014). They were first used by the Kuahuqiao people to cultivate wetlands during a period when wetland areas shrank significantly (ZPICHA and XM 2004). Between 7000 and 5000 B.P., the Lower Yangzi Basin was divided into two major cultural zones: the Hemudu Culture on the Ningshao Plain, south of Hangzhou Bay; and the Majiabang-Songze Cultures in the Lake Taihu area, north of Hangzhou Bay (Figure 1). By 5000 B.P., the basin saw the emergence of a chiefdom-level Liangzhu society, which was centered in the Lake Taihu area with extensive territory to the south.

\section{Hemudu Culture}

Sites of the early Hemudu Culture (7000-6000 B.P.) are concentrated in swampy and flood-prone lowlands close to the foothills of the Simingshan Range on the Ningshao Plain. Sites were situated adjacent to freshwater bodies but also near the ocean, an area covered by paleo-coastal sediments. The villages, $10,000-50,000 \mathrm{~m}^{2}$ in area, were composed of pile-dwelling houses (i.e., wooden platforms raised on stilts). Typical forms of landscape modification included pits for a variety of purposes (e.g., storing food and supporting poles), rice fields, and burials. As far as we know Hemudu Culture was egalitarian (Sun 2013).

The Hemudu rice fields were located on natural freshwater wetlands and were cultivated without water management (Fuller and Qin 2010; Nakajima et al. 2012; Zheng et al. 2009). The rice fields associated with the early Hemudu habitation site at Tianluoshan lie west of the habitation area and at lower elevations over 6.3 ha. At approximately 6000-4500 B.P., a period spanning the late Hemudu Culture through the Liangzhu Culture, rice fields were expanded to 7.4 ha (Zheng et al. 2009). Brackish water may have occasionally intruded and interrupted rice pro- 


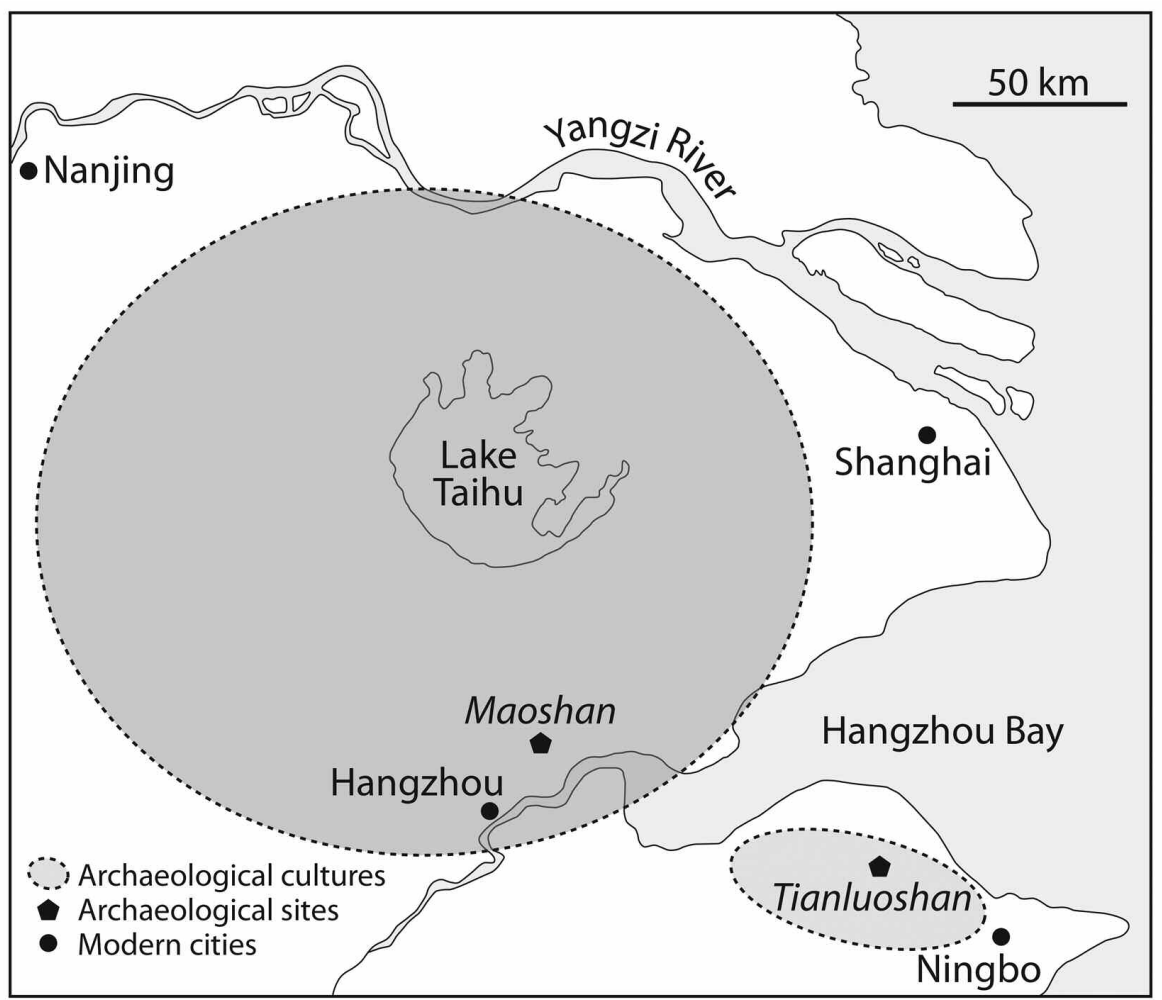

Figure 1. Locations of Hemudu (small gray oval) and Majiabang-Songze (large gray circle) Cultures in the Lower Yangzi Basin and the locations of the Tianluoshan and Maoshan sites where digging experiments were conducted.

duction (Zheng et al. 2012). After a severe marine water inundation around 6400-6300 B.P., villages relocated to slightly higher elevations; this marks the beginning of the transition from early to late Hemudu Culture.

Late Hemudu villages are mainly sited on yellowish soil (probably the Xiashu "Loess," common in the lower Yangzi Basin [Zheng et al. 2002]) but settlement also extended into the wetlands. As the distribution of late Hemudu sites expanded village numbers increased; however, most villages shrank to smaller than $10,000 \mathrm{~m}^{2}$. Anthropogenic deposits are thinner than at early Hemudu sites and have yielded proportionately fewer artifacts and features. The ceramics changed to a degree that many regard as indicative of a different archaeological culture (Ding 1999; Jiang 1999). Forms of landscape modification included houses, pits, burials, and wells. Houses were no longer raised on poles. Natural wetlands continued to be used as rice fields.

Bone spades crafted from large mammal scapulae are frequently found at early Hemudu sites (Xie 2014; ZPICHA 2003). Use-wear studies identified those crafted from water buffalo scapulae dominantly were used as earth-working tools, both for tillage in the rice fields and for digging in the residential zones (Xie 2014).

The number of scapular spades decreased markedly at the end of the early Hemudu Culture; meanwhile, a small number of stone spade-like implements appeared on the Ningshao Plain. For example, we identified five fragmentary pieces at Tianluoshan. Perforated "axes" or yue, previously used in the Majiabang Culture, appeared first at the beginning of the late Hemudu period, with numbers increasing consistently over time (Hemudu Project Committee [HPC] 1999; ZPICHA 2003). These spade-like groundstone implements were crafted from bedded tuff and fine-grained sandstone. Although commonly assumed by Chinese archaeologists to have been symbols of power, at least some of the yues may have been used as earth-working implements 
(Cunnar 2007:255). The adoption of these spadelike stone implements on the Ningshao Plain indicates a major cultural adjustment regarding land-use strategies during this period.

We cannot completely exclude the possibility that declining numbers of scapular spades from early to late Hemudu relate to changing conditions of preservation. However, late Hemudu deposits at Tianluoshan contain significant amounts of bone such as scapulae of small mammals that are more susceptible to chemical or mechanical degradation than water buffalo scapulae. Consequently, the rarity of scapular implements in late Hemudu deposits could have been a function of changing human behavior and not of taphonomy.

Many changes observed in the late Hemudu Culture may have resulted from a combination of inundation caused by severe marine transgression and strong cultural influence from the Majiabang and subsequent Songze populations originating in the Lake Taihu area, perhaps involving immigration of the Majiabang-Songze people to the Ningshao Plain (Ding 1999; HPC 1999; Jiang 1999; Wang 2009). Interestingly, although living on the wetlands during periods of fluctuating sea levels may have been challenging, Hemudu peoples did not relocate to higher ground until cultural influences from the north intensified.

\section{Majiabang-Songze Cultures}

The Majiabang (7000-5800 B.P.) and Songze (5800-5300 B.P.) cultures are concentrated around the Lake Taihu area. So far about 80 sites have been found for each period. Most sites extended to tens of thousands of square meters (Zheng 2008). Ground-level or semi-subterranean houses had wooden (Majiabang) or wattle-anddaub (Songze) superstructures. Large public cemeteries, with hundreds of burials, are known from both cultures (Qin 2013). Overall, the excavated sites display more intensive land use and larger-scale landscape modifications than do Hemudu sites, including pits, houses, wells, ditches enclosed villages, and paddy rice fields.

Artificial rice fields appeared in the late Majiabang period (6300-5800 B.P.), first at Caoxieshan and later at Chuodun. Initially situated in naturally formed shallow depressions, rice fields later took the form of smaller, artificial units with canals and reservoirs dug into the Xiashu Loess (Yang et al. 2007; Zou et al. 2000:107). Agriculture-dominated subsistence strategies developed rapidly after the appearance of these artificial fields (Fuller and Qin 2009). Scapular spades were used in small numbers early in Majiabang Culture, with only four pieces found at Luojiajiao (Luojiajiao Archaeological Team [LAT] 1981) and one at Caoxieshan (Ding 2011). Groundstone artifacts, including the perforated groundstone "axes" called yue were more commonly used. Antler picks may also have been employed (LAT 1981; Zou et al. 2000).

\section{Liangzhu Culture}

Liangzhu Culture (5300-4200 B.P.) was characterized by large-scale landscape modifications, evident in large numbers of sites, large artificial rice fields, many massive earthen platforms, and a walled town. Four hundred Liangzhu Culture sites have been found around Lake Taihu. Most are located on artificially graded ground on top of natural hills (Qin 2013). Over 20 massive earthen platforms for elite cemeteries and/or ritual activities are also known (Institute of Archaeology 2010). A large walled town enclosing a rectangular area of about 290 ha, with surrounding walls 6.6 to $7.2 \mathrm{~km}$ long, was built in the late Liangzhu period (4600-4200 B.P.) (Liu 2009; ZPICHA 2008). The walls, $40-60 \mathrm{~m}$ wide and up to $4 \mathrm{~m}$ in remaining height, were built with pure yellowish clay on a layer of stone blocks (Liu 2009; ZPICHA 2008). The construction of these walls required approximately $1,380,000 \mathrm{~m}^{3}$ of soil.

Liangzhu society was based on a full-scale agricultural economy with extensive paddy rice fields (e.g., Maoshan, see Ding et al. 2010, 2011). Not coincidentally, large numbers of groundstone yue and plow-like implements, mainly crafted from hornfels and tuff, were employed by the Liangzhu Culture (Qin 2013; Zhao 2007:176). Social hierarchies are remarkably evident in the Lake Taihu area (Qin 2013). Although the Ningshao Plain may also have been included in the Liangzhu territory, material remains in this area appear to include only those from the non-elite ranks of the society (Ding 1999). 


\section{Testing Alternative Earth-moving Technolo- gies: Experimental Design and Methods}

Archaeologists acknowledge that the effectiveness and durability of simple earth-working implements may have been significantly affected by soil conditions (e.g., Curwen 1926; Huang 1996; Milner et al. 2010; Yu 1993), but little research has been conducted to evaluate these expectations. Ethnographic information suggests general associations between soil textures and implement choices. For example, wooden implements are often used in sandy and/or stony substrates while bone and wooden spades are preferred for loose soil (e.g., Baker 1936; Best 1976; Clark 1959:239; Kirch et al. 2005; Wilson 1917).

Experiments in agricultural science repeatedly identify a negative correlation between root penetration rate and soil penetration resistance (PR hereafter) values (e.g., Bengough and Mullins 1991; Martino and Shaykewich 1994; Sinnett et al. 2008). The mechanical action of an earthworking implement breaking through soil is similar to roots penetrating earth; therefore, one can expect that soil PR affects the performance of earth-working implements as well. With metal tools the labor requirement for digging quadruples as the soil type changes from soft to dry hard clay (Hammerstedt 2005:Table 2).

In order to understand associations between the performance of earth-working implements and soil conditions, the senior author designed a set of controlled experiments in a range of soils representative of those with which the prehistoric farmers in the Lower Yangzi Basin had to contend. Technofunctional performance characteristics examined through these experiments include (1) digging efficiency, quantified as time and energy costs for the tasks and also evaluated qualitatively by means of the experimental participant comments; and (2) measurement of the attrition rates of implements made of both bone and stone.

Here we report on our investigation of correlations between the performance characteristics of implements and soil PR and particle sizes, respectively. We also investigate whether or not soils from actual sites associated with different kinds of digging tools match the physical properties of the experimental plots used in our experiments.

Our experiments were designed to measure performance characteristics of breaking ground, on the assumption that this task affected technological choices on earth-working implements more directly than soil removal and transportation. Pilot experiments showed that scapular earth-working implements can break earth in Lower Yangzi Basin soils only when hafted as shovels rather than hoes (Supplemental Note 1); therefore, our systematic experiments focused only on shovel performance.

We evaluate the efficiency of tillage by the depth of penetration and tilling area with respect to the time, energy, and raw material expended, given that the earth must be cut, scooped up, and aerated deeply enough for rice cultivation. By contrast, we measured the volume of soil being loosened as a benefit of the costs for earthen construction. We then determine whether or not the differences between bone and stone shovels are statistically significant and/or of practical consequence.

Our experimental fields include wetland sediments and the Xiashu Loess commonly present in the lower Yangzi basin, modern and ancient rice fields, and burial and habitation loci associated with the sites occupied by the Hemudu, Majiabang, Songze and Liangzhu people. All of the ancient anthropogenic fields date to ca. 70004000 B.P.

In each soil type, digging experiments were conducted by a minimum of three skilled male farmers. Experimental earth-working implements (Table 1) were replicated using locally derived archaeological samples as templates. Our bone shovels were crafted from modern cattle scapulae; most implements' edges were straight but slightly concave due to the constraints imposed by the natural morphology of scapulae. Our stone shovels were crafted from oolitic dolomite, a material used at middle Neolithic to early Bronze Age sites in central China (Webb et al. 2007); all edges were convex (Figure 2). These raw materials share mechanical properties with those used prehistorically.

Each farmer participating in the experiment was asked to complete paired experiments using scapular and stone implements. Each tool was used to till (i.e. break through and turn over soil) or simply "break" the earth (regular digging) in a plot varying from .6 to $2 \mathrm{~m} 2$, depending on the 
Table 1. Experimental Digging Implements.

\begin{tabular}{|c|c|c|c|c|c|c|c|c|}
\hline Field\# & ID & Material & $\begin{array}{c}\text { Net } \\
\text { Wt }(g)\end{array}$ & $\begin{array}{l}\text { Hafted } \\
\text { Wt. (g) }\end{array}$ & $\begin{array}{c}\text { Length } \\
(\mathrm{cm})\end{array}$ & $\begin{array}{r}\text { Width } \\
(\mathrm{cm})\end{array}$ & $\begin{array}{l}\text { Edge } \\
\text { Angle }\end{array}$ & Edge Morphology \\
\hline \multirow[t]{2}{*}{ I } & 6002 & Bone & 367.5 & 968.0 & 20.8 & 15.4 & $30-35$ & Straight, slightly uneven \\
\hline & 4008 & Stone & 362.0 & $1,029.0$ & 11.7 & 14.9 & $32-36$ & Convex \\
\hline \multirow[t]{2}{*}{ II } & 6013 & Bone & 248.6 & 843.2 & 18.7 & 11.5 & $22-30$ & Straight, slightly concave \\
\hline & 4003 & Stone & 572.7 & $1,451.3$ & 13.9 & 13.0 & $30-38$ & Convex \\
\hline \multirow[t]{2}{*}{ III } & 6011 & Bone & 250.0 & 832.0 & 18.6 & 10.7 & $25-29$ & Straight, slightly concave \\
\hline & 4007 & Stone & 521.8 & $1,384.0$ & 12.8 & 12.3 & $39-43$ & Slightly convex \\
\hline \multirow[t]{2}{*}{ IV } & 6020 & Bone & 417.0 & $1,062.0$ & 22.5 & 15.5 & $30-37$ & Straight, slightly uneven \\
\hline & 4002 & Stone & 587.1 & $1,520.0$ & 16.8 & 11.0 & $28-30$ & Convex \\
\hline \multirow[t]{2}{*}{$\mathrm{V}$} & 6021 & Bone & 262.9 & 835.5 & 18.4 & 12.9 & $20-22$ & Straight, slightly concave and uneven \\
\hline & 4013 & Stone & 700.3 & $1,539.2$ & 16.7 & 11.7 & $26-27$ & Convex \\
\hline \multirow[t]{2}{*}{ VI } & 6004 & Bone & 311.0 & $1,368.0$ & 20.3 & 13.1 & $30-35$ & Slightly concave \\
\hline & 4002 & Stone & 587.1 & $1,521.0$ & 16.7 & 11.0 & $28-30$ & Convex \\
\hline \multirow[t]{2}{*}{ VII } & 6004 & Bone & 312.0 & $1,369.0$ & 20.0 & 13.1 & 25 & Straight, slightly concave \\
\hline & 4011 & Stone & 513.6 & $1,461.0$ & 16.7 & 10.9 & $24-28$ & Convex \\
\hline
\end{tabular}

ease of work and/or appropriate soil conditions. After each experiment, the volume of worked soil was calculated.

Soil PR and particle size were measured in each experiment in order to assess the relationships between performance characteristics and the working environments. This allows us to predict the performance characteristics of earthworking implements in prehistoric contexts without additional experiments. We also measured raw material attrition rates in digging activities and calculated the implements' potential use lives.

\section{Physical Properties and Cultural Contexts of the Worked Soils}

Soil PR is quantified by how much force is needed to penetrate through a unit area of soil (e.g., kilograms per square centimeter). We employed a cone penetrometer to assess PR in the experimental fields before each experiment (Supplemental Note 2). We also measured soil water content, a variable that directly affects PR (Martino and Shaykewich 1994). Paired information on water content and PR will allow better estimate
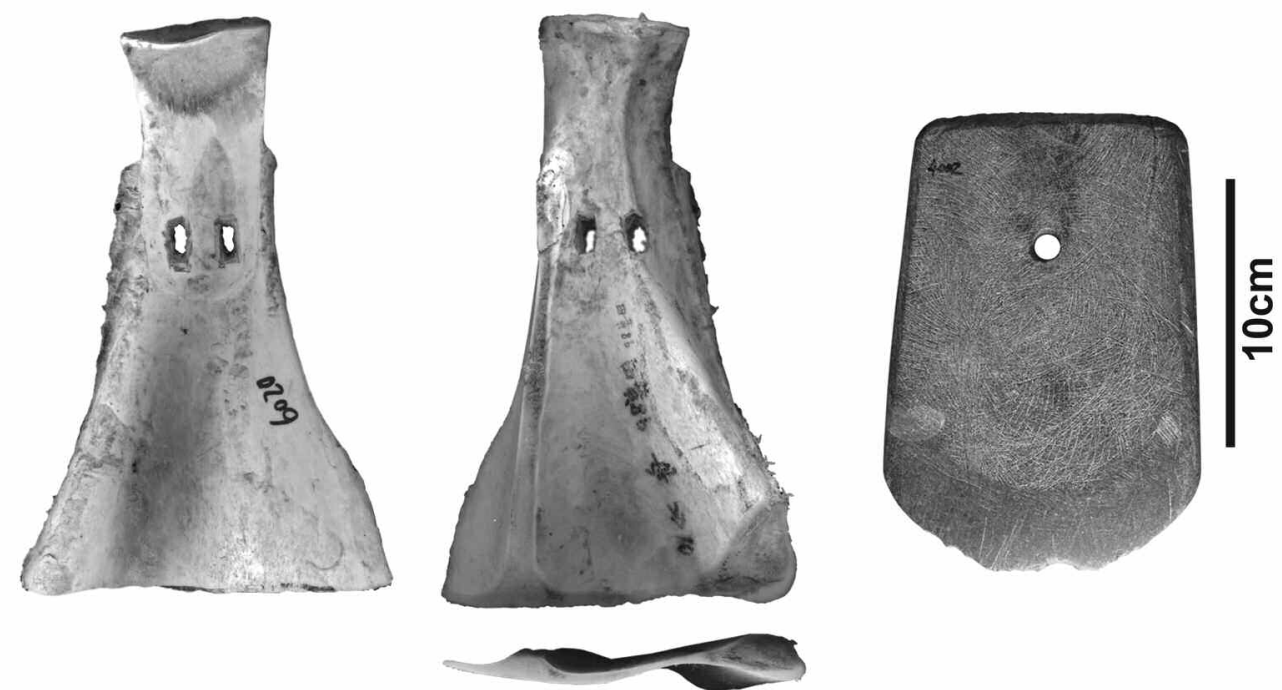

\section{Experimental tool 6020}

Figure 2. Sample experimental implements: a scapular spade (left: dorsal, ventral, and edge views) and a groundstone spade (right). 
Table 2. Cultural Contexts and Physical Properties of Soil in Experimental Fields.

\begin{tabular}{|c|c|c|c|c|c|c|c|}
\hline Field\# & Context & Location & $\begin{array}{l}\text { Date } \\
\text { (k.y.a.) }\end{array}$ & $\begin{array}{c}\mathrm{PR} \\
\left(\mathrm{kg} / \mathrm{cm}^{2}\right)\end{array}$ & $\begin{array}{l}\text { WC } \\
(\%)\end{array}$ & Sand $\%$ & Texture Type \\
\hline $\mathrm{I}$ & Rice Field & TLS $^{\mathrm{a}}$ & Modern & .8 & $>71^{\mathrm{b}}$ & 10.82 & Silt Loam \\
\hline II & Rice Field & TLS & Modern & 2.3 & 70.7 & 6.69 & Silt Loam \\
\hline III & Rice Field & TLS & $4.2-5.3$ & $2.8^{\mathrm{c}}$ & 62.7 & 0.00 & Silty Clay Loam \\
\hline IV & Rice Field & $\mathrm{MS}^{\mathrm{d}}$ & 4.5 & 4.7 & 33.7 & 2.60 & Silty Clay Loam \\
\hline V & Habitation Area & TLS & 6.5 & 9.8 & 56.9 & 21.26 & Silt Loam \\
\hline VI & Xiashu Loess & MS & $>6.8$ & 22.6 & 22.9 & 5.17 & Silty Clay Loam \\
\hline VII & Babitation \& Burial Zones & MS & 6 & 26.4 & 21.1 & 17.91 & Silt Loam \\
\hline
\end{tabular}

${ }^{\text {aTLS }}=$ The Tianluoshan site or the modern Tianluoshan village, Ningbo City, Zhejiang, China.

${ }^{b}$ The number measured was 68.1 , but the actual WC was much higher because the soil was saturated with flowing surface water, and it was impossible to encase the soil well with cling wrap, so the WC was reduced significantly when the soil sample was collected.

'This PR value was originally measured at $1.75 / 16$ to $4 / 16 \mathrm{~kg} / \mathrm{cm}^{2}$ by a pocket penetrometer before a more reliable cone penetrometer was deployed; the earlier figure was evidently inaccurate. A value of 2.8 was arbitrarily estimated afterward according to the soil's hardness compared with those in Fields I, II, and IV, by removing the denominators (16) of the original measurements and averaging the final results.

${ }^{\mathrm{d}} \mathrm{MS}=$ The Maoshan site, Hangzhou City, Zhejiang Province, China.

of the prehistoric working contexts of earth-working implements during dry and wet seasons, in wet and dry lands, or at different "elevations" relative to associated water bodies. Soil samples for laboratory measurement of water content were taken at the same time and in the same places where PR was measured (Supplemental Note 3). Samples for texture measurement were collected from the aggregate soils loosened by the experimental implements and air-dried for particle size analysis (Supplemental Note 4). Table 2 shows the soil properties of the seven fields included in our experiments.

Fields I and II were located near the modern village of Tianluoshan, where 62 early Hemudu Culture scapular tools have been uncovered. The field has been used for growing rice in recent times. Experiments in Field I were conducted between rice-growing seasons in the summer. It was right after rains and so water content exceeded field capacity. Soil so wet and soft does not need to be tilled; however, in constructing piledwellings and wet storage pits before 6,000 years ago in swampy lowlands on the Ningshao Plain, people may have had to dig through soils with similar PR values. Experiments in Field II were conducted in December when the field was much drier. They immediately followed the winter rice harvest, and there were many fresh rice roots and stems but few wild grasses in the field.

Fields III and IV were ancient rice fields used in the Liangzhu cultural period at the Tianluoshan
(TLSIIIT503? and TLSIIIT400?) and Maoshan (MSTS1W30?) sites. Experiments in Field III were conducted after rains; sometimes water was squeezed out when earth-working implements impacted and penetrated the surface. Soil in Field IV was slightly drier.

Field V was an ancient habitation and burial ground at Tianluoshan, occupied during the late stage of the early Hemudu Culture. Heavily weathered rocks were scattered in the field. Unweathered rocks with diameters larger than 10 $\mathrm{cm}$ were also present, on average, 2-3 rocks in each experimental plot. Soil hardness was quite heterogeneous, so the texture and PR values presented in Table 2 were averages of both the soft and hard soil samples.

Field VI and VII were situated in habitation and burial areas at Maoshan. Field VI was the Xiashu Loess, the substrate on which the site was founded (MST0533 beneath Layer 6). Prehistoric peoples excavated graves and pits into this sediment. Field VII was an anthropogenic deposit (MST0533?) directly superimposed on the Xiashu Loess, belonging to the Majiabang Culture. The soils were extremely compacted when dry, with PR exceeding $45 \mathrm{~kg} / \mathrm{cm}^{2}$, and could hardly be penetrated with either bone or stone tools. Even with iron hoes it was difficult breaking through this deposit when it was dry. The soils did not absorb much water: after heavy rains, water pooled in surface depressions for days. Nonetheless sufficient rain does soften them quite well. 


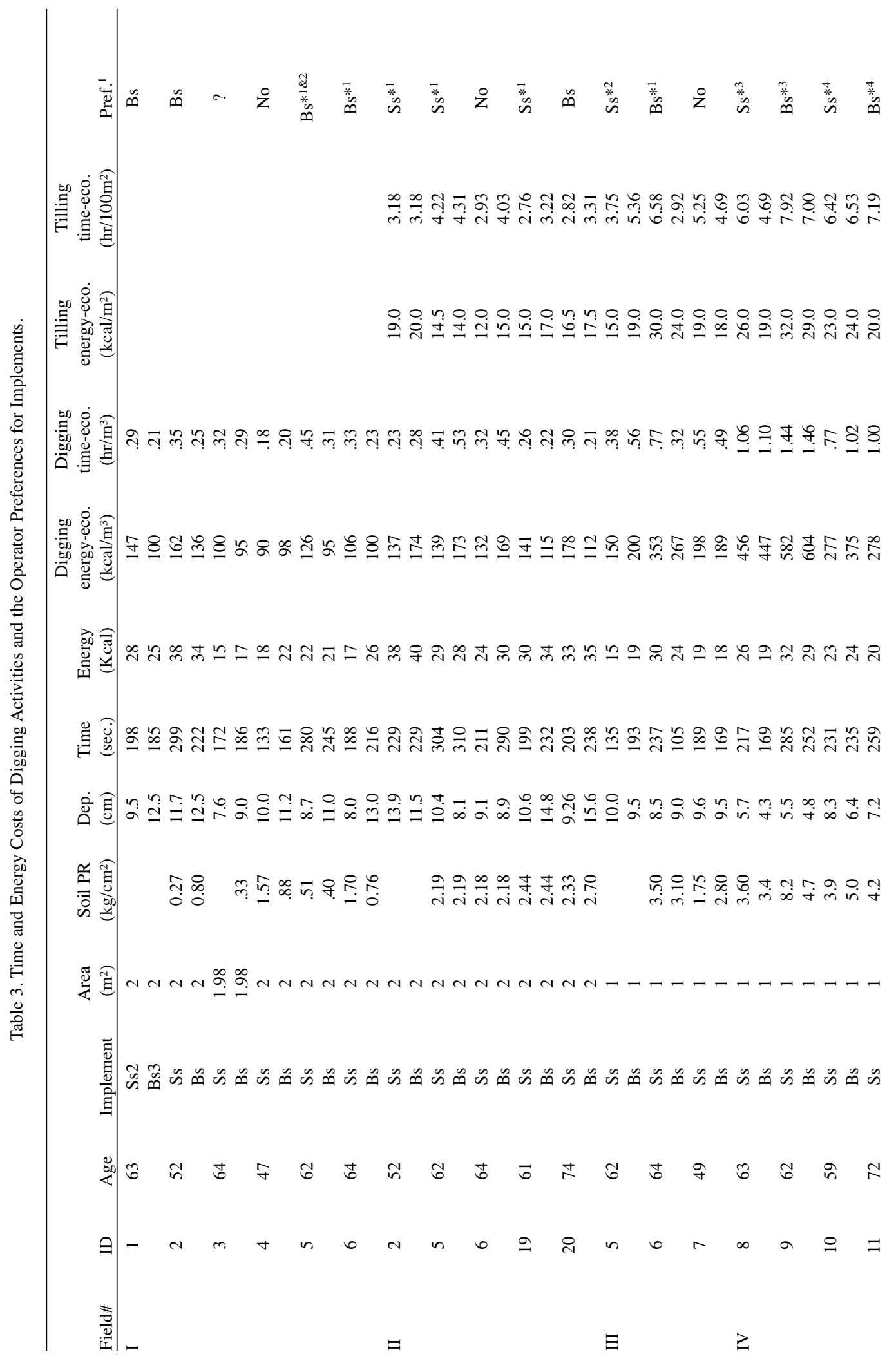


Xie et al.]

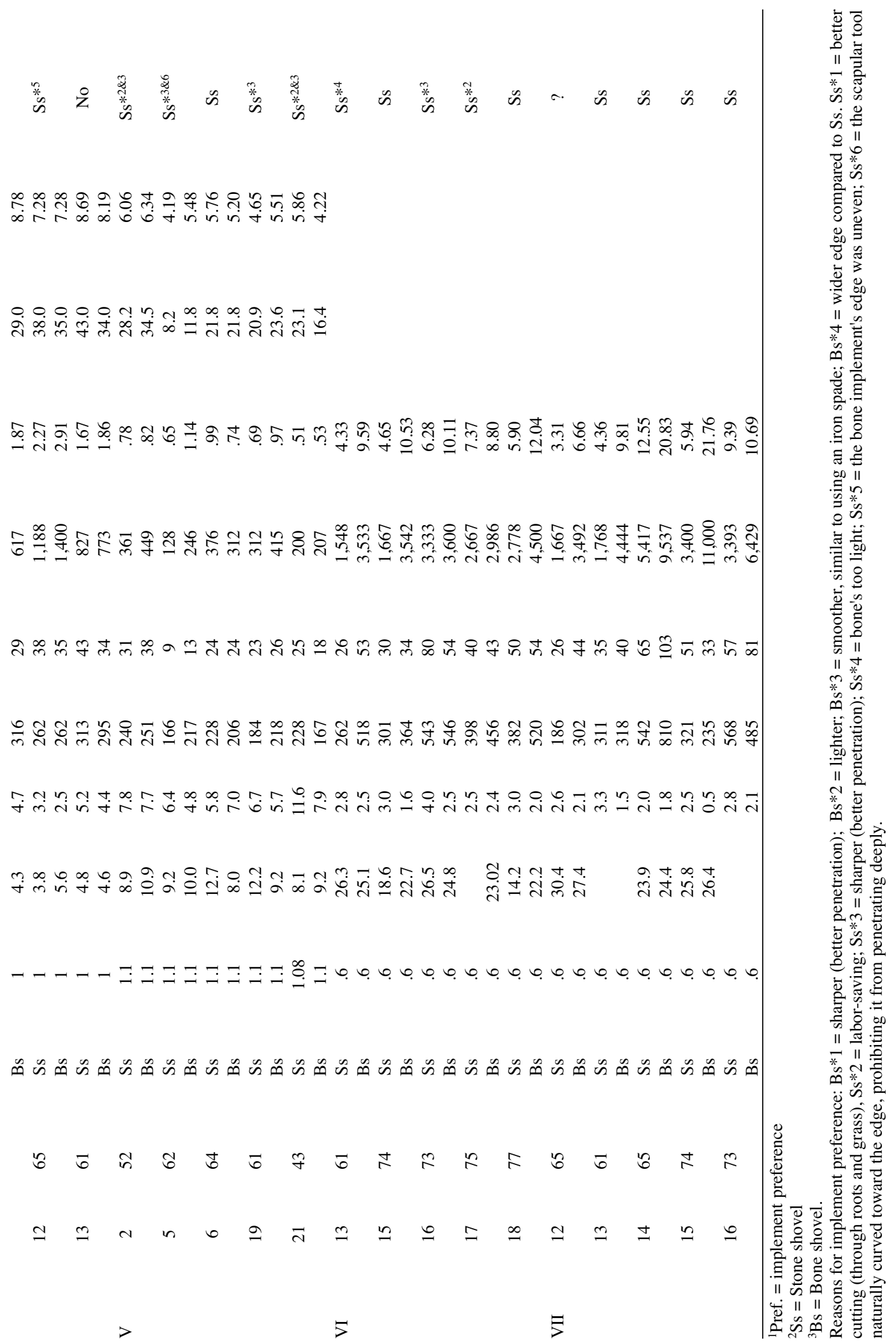


Table 4. Implement Costs (Material Attrition Rates) of Digging.

\begin{tabular}{|c|c|c|c|c|c|c|c|}
\hline Field\# & $\begin{array}{c}\mathrm{PR} \\
\left(\mathrm{kg} / \mathrm{cm}^{2}\right) \\
\end{array}$ & Implement & Material & $\begin{array}{r}\text { Time } \\
(\mathrm{hr})\end{array}$ & $\begin{array}{c}\text { Soil } \\
\text { Removed }\left(\mathrm{m}^{3}\right)\end{array}$ & $\begin{array}{l}\text { Worn-down } \\
\text { Area }\left(\mathrm{cm}^{2}\right)\end{array}$ & $\begin{array}{l}\text { Attrition Rate } \\
\left(\mathrm{cm}^{2} / \mathrm{m}^{3}\right)^{\mathrm{a}}\end{array}$ \\
\hline \multirow[t]{2}{*}{ I } & & 6002 & Bone & .338 & 1.38 & \multirow{2}{*}{\multicolumn{2}{|c|}{$\begin{array}{l}\text { too subtle to be measured } \\
\text { too subtle to be measured }\end{array}$}} \\
\hline & & 4008 & Stone & .353 & 1.11 & & \\
\hline \multirow[t]{2}{*}{ II } & 2.4 & 6013 & Bone & 2.485 & 6.39 & .16 & .025 \\
\hline & 2.3 & 4003 & Stone & 4.021 & 10.70 & .14 & .013 \\
\hline \multirow[t]{2}{*}{ III } & 2.9 & 6011 & Bone & .130 & .28 & .02 & .080 \\
\hline & 2.6 & 4007 & Stone & .156 & .28 & .06 & .041 \\
\hline \multirow[t]{2}{*}{ IV } & 4.6 & 6020 & Bone & .425 & .27 & 1.36 & 4.607 \\
\hline & 4.7 & 4002 & Stone & 2.75 & .87 & 3.05 & 1.774 \\
\hline \multirow[t]{2}{*}{ V } & 9.5 & 6021 & Bone & .327 & .37 & 7.29 & 19.181 \\
\hline & 10.2 & 4013 & Stone & .305 & .42 & 1.17 & $>2.782^{b}$ \\
\hline \multirow[t]{2}{*}{ VI } & 23.6 & 6004 & Bone & .668 & .07 & 1.10 & 15.690 \\
\hline & 21.4 & 4002 & Stone & 1.149 & .21 & 1.55 & 7.360 \\
\hline \multirow[t]{2}{*}{ VII } & 26.1 & 6004 & Bone & .597 & .05 & 2.00 & 40.097 \\
\hline & 26.7 & 4011 & Stone & .536 & .08 & .66 & 8.202 \\
\hline
\end{tabular}

${ }^{a}$ Attrition rate $\left(\mathrm{cm}^{2} / \mathrm{m}^{3}\right)$ indicates how much area was worn down from the edge by digging up one cubic meter of soil. ${ }^{\mathrm{b}} \mathrm{A}$ value of $2.782 \mathrm{~cm}^{2} / \mathrm{m}^{3}$ under-estimated the attrition rate due to a failure of experimental control when one operator avoided edge damage from the stone implement (see below).

Digging experiments were conducted between rains when water content was highest.

\section{Measuring Energy and Time Costs}

We used the heart-rate-based caloric consumption calculation to estimate the energy costs of digging (Supplemental Note 5). We then evaluated the digging efficiency as time and energy costs for completing a unit plot of tilling $\left(\mathrm{kcal} / \mathrm{m}^{2}\right.$ and $\mathrm{hr} / \mathrm{m}^{2}$ ) and/or for loosening a cubic meter of earth $\left(\mathrm{kcal} / \mathrm{m}^{3}\right.$ and $\left.\mathrm{hr} / \mathrm{m}^{3}\right)$. Both tilling and regular digging efficiency were calculated with data generated from experiments in Fields II-V, assuming that, in prehistory, the PR values of these soils could be in the range of both agricultural and non-agricultural fields. However, data generated from experiments in Fields I, VI, and VII are useful only for assessing regular digging activities because tilling activities would hardly have taken place in these soil that was either too soft for tillage or too compacted for rice to grow. Table 3 summarizes the time and energy efficiency of digging activities and implement preferences of the experimental subjects.

\section{Measuring Implement Costs: Attrition Rates}

Implement costs of digging activities were calculated as the value of the worn-down area $\left(\mathrm{cm}^{2}\right)$ of the spades divided by the mass of soil removed $\left(\mathrm{m}^{3}\right)$, indicating how much of the implement material was consumed by moving one cubic meter of soil (Supplemental Note 6). This is also called attrition rate, based on which use lives of earthworking implements made from stone and cattle scapulae were estimated (see details below).

Experimental implements used in the paired experiments for the purpose of measuring energy and time costs were not always worn down to a measurable extent; therefore, after the paired experiments, some of the implements continued to be used until they were measurably worn down. Table 4 presents the results on implement costs.

\section{Statistical Analyses and Results}

\section{Comparing Time and Energy Costs of Digging with Bone and Stone Implements}

Because time and energy costs of digging activities varied greatly from person to person (Table 3), paired-sample comparisons instead of regular comparisons of central tendency were employed to evaluate the differences between the performance characteristics of stone and scapular implements and the significance of the differences was tested with Wilcoxon's Signed-rank Test (Table 5).

In Field I, the softest soil matrix, the bone implement was significantly more time-efficient for regular digging $(M D=.07, W=5, Z=9.5, p=$ .0313). Although the bone implement appeared to also function more efficiently as measured by 


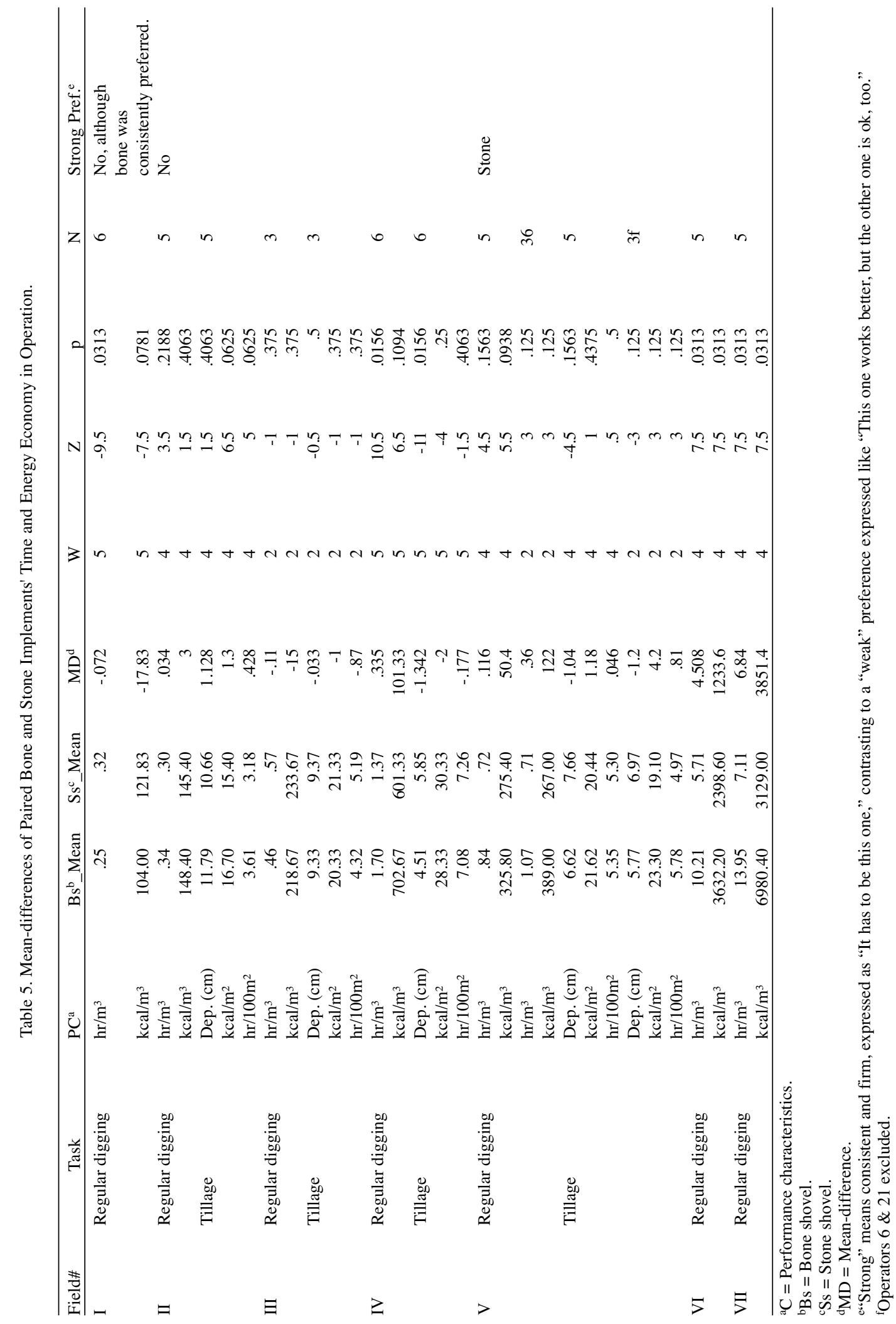


energy expenditure, the difference is not statistically significant $(M D=17.83, W=5, Z=7.5, p$ $=.0781$ ). The operators' preferences (Table 3 ) are quite consistent with the statistical results: four out of five operators who commented on the implements preferred bone, for its light weight and/or "sharpness."

Some operators were very sensitive to even very subtle differences in the implements' weight (968 g vs. $1029 \mathrm{~g}$ when hafted). This perhaps resulted from additional stress generated by maintaining body balance in the soft, sticky soil. The comment on a tool's "sharpness" referred to subjective judgments of a tool's ability to penetrate soil. Although a bone shovel was perceived as "sharper" than a stone shovel in Fields I and III, it was perceived as "blunter" in Fields V-VII, regardless of the implements' exact edge angles and how sharp they were compared to one another.

Experimental results from Field II showed no patterns between stone and bone shovels (Table $3)$. Results for regular digging from Operators 2, 5 , and 6 were completely opposite of those of Operators 19 and 20. For example, Operators 2, 5 , and 6 dug more efficiently with a stone implement. In contrast, Operators 19 and 20 dug better with a bone shovel. Interestingly, Operator 19 expressed his slight preference for a stone one, suggesting that the differences in time and energy efficiency between bone and stone implements were too subtle to be noticed by tool users.

The operator preference for either material was vague. The only operator who preferred bone could not adequately explain why he thought that material was better. Although three out of four operators who commented on the implements preferred stone because of its ability to cut through live or fresh roots and grasses in the soil, they also pointed out that in reality farmers would not till their fields until after the roots and stems rotted and could be easily cut. In fact, one year before these experiments were conducted, pilot experiments were conducted in the same field, with Operators 5 and 6 involved. It was about a month and two heavy snows after winter harvest and the roots and stems were rotted; at that time both operators preferred the bone implement for its "sharpness" regardless of the fact that it functioned slightly less efficiently than the stone implement (Supplemental Note 7).
Experimental results from Field III also showed no systematic differences between stone and bone shovels. For instance, Operator 5 tilled the field more efficiently with a stone implement while Operator 6 was more efficient with a bone implement. The operators themselves perceived the differences between the two implements during their use (Table 3). However, these "differences" are likely individual. A third operator used the same pair of implements almost equally well and expressed no preference. Limited by the area available for this set of experiments, only three paired experiments were conducted; however, it is safe to conclude that stone and bone were equally likely to have been adopted for working in such fields, if the decision was made simply based on the implement's penetration ability, and time and energy efficiency in operation.

In Field IV, the stone implement performed significantly better in terms of time-economy $(M D=.34, W=5, Z=10.5, p=.0156, n=6)$ for regular digging and in penetrating soil as a tilling implement $(M D=1.34, W=5, Z=10.5, p=$ $.0156, n=6)$. However, there were no other significant differences in working efficiency between the two materials. In practice, the subjects showed no pattern of preference. The better penetration of the stone implement, although statistically significant, was noticed by only one operator out of six. Reasons given by the operators for their preferences for stone instead focused on the deterioration of the bone shovel's edge more than on any intrinsic property of stone, suggesting that bone could have been preferred if the bone shovel had been in better shape. Observations about positive features of the bone shovel included smoother surface (thus encountering less resistance when penetrating soil) and wider edge, which are advantages of scapular material. Certainly stone shovels could be made smooth and broader-edged, but the processes would require larger pieces of raw material and craftspeople of better knapping skill.

There was a clear distinction between how well the implements worked in Fields V-VII. The stone implement worked consistently better than the bone variant, a fact that all participants noted right away. Without exception, stone shovels were preferred in all three fields.

In Field V, all five operators perceived the 
stone implement as labor-saving and offering better penetration and/or an ideal morphology. The natural curved morphology of cattle scapulae prohibited them from penetrating deeply in the hard soil in this field. Experimental results from Operators 2, 5, and 19 (Table 3) suggested that the stone shovel worked better regarding efficiency of time and energy (for time efficiency, $M D=$ .36, $W=2, Z=3$; for energy economy, $M D=$ $122, W=2, Z=3$. The $p$ values are both .125 . Although not statistically significant in conventional terms, it is the best possible result for a sample size of three. To test a bigger sample, we combined the results with those from Field VI and not surprisingly the difference became significant when the sample size was increased to eight, (with a $p$ value decreased to .0039). Numeric results from Operators 6 and 21 showed otherwise, with the bone implement working better than the stone one (Table 3), but those data were not reliable due to failures of experimental controls (Supplemental Note 8). Nonetheless, both Operators 6 and 21 expressed clear preferences for stone shovels.

Soil in Field V, although relatively hard, seemed tillable; the operators "tilled" it to depths of $8-12.7 \mathrm{~cm}$ by a single stroke. Compared to bone, stone penetrated the earth deeper $(M D=$ $1.2, W=2, Z=3$ ) and dug more efficiently (for time economy, $M D=.81, W=2, Z=3$; for energy economy, $M D=4.2, W=2, Z=3)$. Again, the $p$ values are .125 , the best possible result for a sample size of three.

Soils in Fields VI and VII were much harder than those in Fields I-V. Tillage proved not to be feasible. Neither stone nor bone implement could prepare the field for growing rice. Therefore, only worked volume but not worked area was considered as an indicator of digging efficiency. In these two fields, especially in Field VII, the operators proposed that the bone shovel should not be used at all. Statistically, stone shovels worked consistently and significantly better than their bone counterparts. In Field VI, on average stone required 79 percent less time and 51 percent less energy for digging ( $W=4, Z=7.5, p=.0313, n$ $=5$ ). The differences in Field VII were extreme: the stone shovel required 96 percent less time, and 123 percent less energy than the bone shovel for digging ( $W=4, Z=7.5, p=.0313, n=5)$.
When working in soils as compacted as those in Fields V-VII, stone implements also can be hafted as hoes and achieve even greater impact ability and higher efficiency (Supplemental Note 9). Bone implements could not penetrate moderately packed earth when hafted as hoes; they were notably less efficient than stone shovels, and certainly could not compete with stone hoes. Therefore, bone implements would be unlikely to be employed in soils as compacted as those in Fields V-VII, especially VI and VII. When suitable stone raw materials or implements were unavailable, prehistoric populations may have preferred using technologies similar to wooden digging sticks for penetrating such soils, as evidenced at the site of Kuahuqiao (ZPIACH 1997).

Overall, the relationship between soil PR and spade digging efficiency regarding time and energy economics is obvious and statistically significant (Figure 3). Differences between material types varied among PR value zones. There was virtually no difference between the two raw materials for soft to moderately compacted soils, whereas the difference was very pronounced in harder-packed soils. Statistically, the digging efficiency of bone implements was slightly better than stone in extremely soft soil, as in Field I where PR value was lower than $1 \mathrm{~kg} / \mathrm{cm}^{2}$, and bone was indeed preferred by most tool users for its light weight and/or better penetration ability. There were neither statistically significant differences nor consistent, strong preferences expressed for implements when dealing with soils with PR values of $1-4 \mathrm{~kg} / \mathrm{cm}^{2}$. Although differences between bone and stone approach statistical significance when a PR value exceeded $4 \mathrm{~kg} / \mathrm{cm}^{2}$, as in Field IV, the differences were not noticed by the tool users until the PR values reached a much higher value, probably around $8 \mathrm{~kg} / \mathrm{cm}^{2}$, according to participants' comments in Field V. In soils with PR values greater than $8 \mathrm{~kg} / \mathrm{cm}^{2}$, stone performed significantly better than bone and it was always preferred by the tool users.

In short, from a technofunctional perspective, bone might have been preferred when soil was extremely soft (with PR $<1 \mathrm{~kg} / \mathrm{cm}^{2}$ ) and stone would have been preferred in relatively hardpacked soil (with PR $>8 \mathrm{~kg} / \mathrm{cm}^{2}$ ). In soils with PR values of $1-8 \mathrm{~kg} / \mathrm{cm}^{2}$, people would have little basis for choosing among different raw ma- 

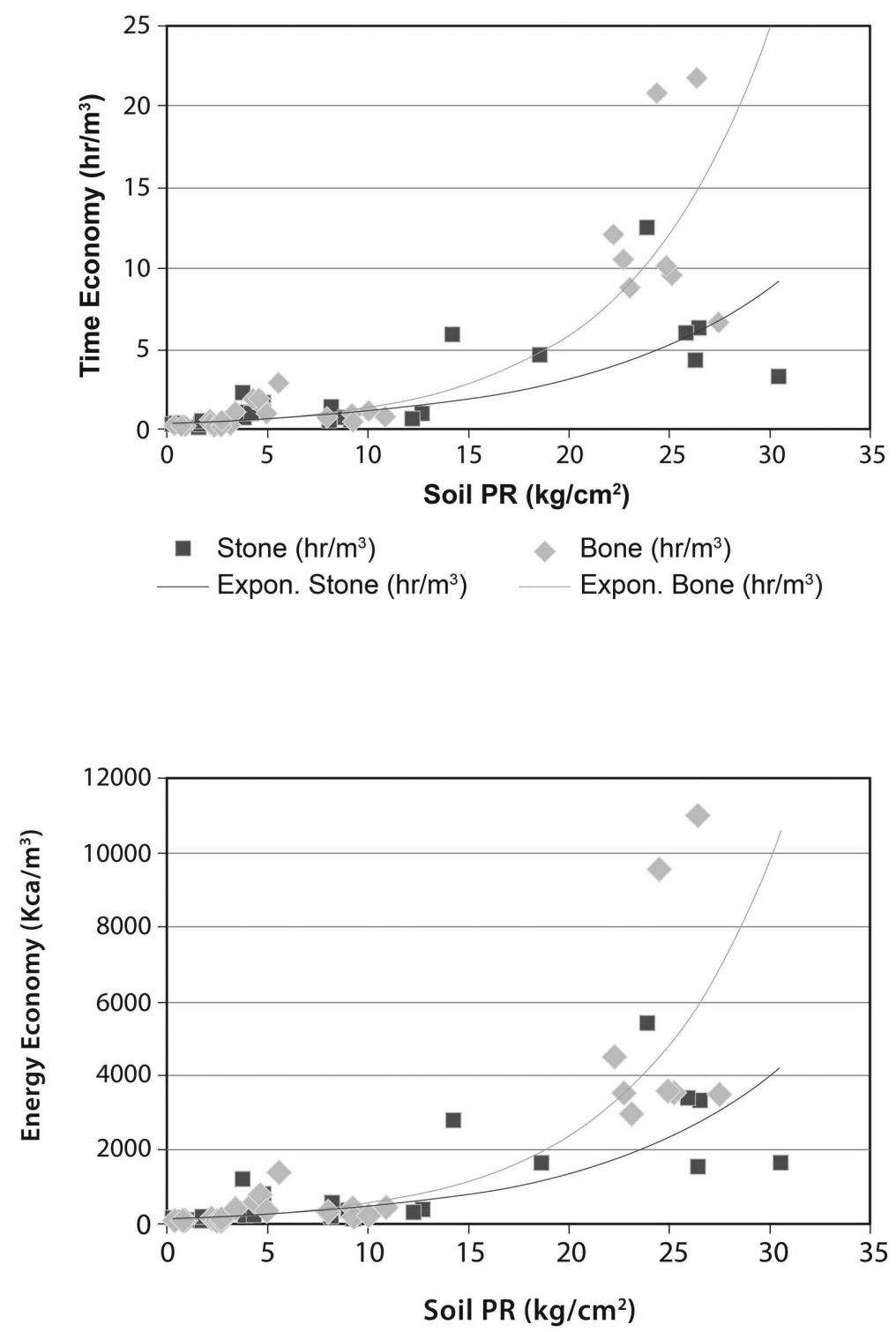

Figure 3. Exponential regression of digging efficiency of bone and stone implements and soil penetration resistance (PR). Gray (bone) and black (stone) squares along the trend lines indicate results from actual experiments. Bone $\left(\mathrm{hr} / \mathrm{m}^{3}\right)=$ $.3244^{1448 * \mathrm{PR}}\left(r^{2}=.83, p<.0001, n=29\right)$; Stone $\left(\mathrm{hr} / \mathrm{m}^{3}\right)=.4063^{1024 * \mathrm{PR}}\left(r^{2}=.69, p<.0001, n=28\right)$; Bone $\left(\mathrm{kcal} / \mathrm{m}^{3}\right)=$ $136.27^{143 * \mathrm{PR}}\left(r^{2}=.84, p<.0001, n=29\right) ;$ Stone $\left(\mathrm{kcal} / \mathrm{m}^{3}\right)=159.63^{1076^{*} \mathrm{PR}}\left(r^{2}=.68, p<.0001, n=28\right)$.

terials for digging tools based on functional properties alone.

All discussions above regarding tool preferences only indicated situations with an adequate supply of implements. To better predict long-term outcomes of daily activities and decisions, the use lives of earth-working implements must also be considered.

\section{Comparing Attrition Rates and} Use Lives of Bone and Stone Spades

Attrition Rates. In all experimental fields but Field I, earth-working implements were worn down measurably through use (Table 4). The attrition rates of both bone and stone were significantly related to PR (Figure 4). There was little difference between bone and stone's attrition rates 

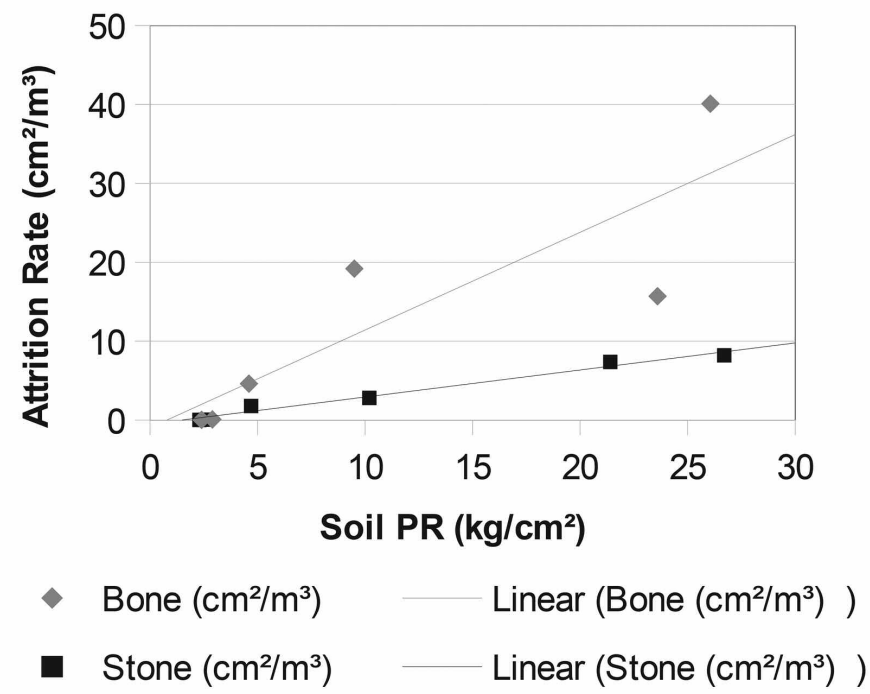

Figure 4. Linear regression of bone and stone attrition rates and soil penetration resistance (PR). Gray (bone) and black (stone) squares along the trend lines indicate results of experiments carried out in Fields II-VII. Bone attrition rate = $.934819+1.2542487 * \mathrm{PR}(r 2=.71, p=.0345, n=6)$; stone attrition rate $=-.51193+.3423208 * \mathrm{PR}(r=.98, p=.0001, n=6)$.

in soft soils, whereas the difference was very pronounced in harder-packed soils.

Although soil PR determined the attrition rates of both bone and stone to a great extent, its effects on the two materials differed as the PR ranges changed. When the PR value was lower than 3 $\mathrm{kg} / \mathrm{cm}^{2}$, as in Fields II and III, bone and stone attrition rates appeared to be almost identical (Figure 5). However, in harder soils, the attrition rates of bone and stone tools diverged. In Fields IV-VII $\left(\mathrm{PR}=4.7-26.7 \mathrm{~kg} / \mathrm{cm}^{2}\right)$, although soil PR alone still significantly affected stone's attrition rate, the attrition rate did not increase as rapidly as in softer soil (Figure 6). In a similar PR range, PR alone no longer determined bone attrition rate $\left(r^{2}\right.$ $=.53, p=.2738, n=4)$. However, a combination of soil PR and percentage of sand (by multiplying PR values by percentages of sand) predicted bone attrition rate extremely well (Figure 7).

Use Lives. Based on bone and stone attrition rates, we estimated the use lives of spades crafted from these two materials. Due to constraints im-

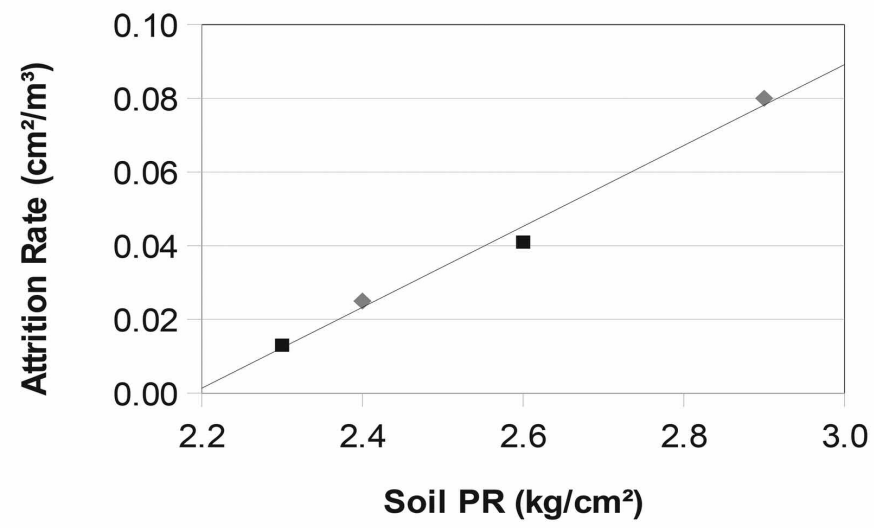

Figure 5.Attrition rates of both bone and stone as predicted by soil penetration resistance values (PR) when PR $<3$ $\mathrm{kg} / \mathrm{cm}^{2}$. Gray (bone) and black (stone) squares along the trend lines indicate results from actual experiments in Fields II-III. Attrition rate $=-.240143+.1097619 * \mathrm{PR}\left(r^{2}=.99, p=.0049, n=4\right)$. 


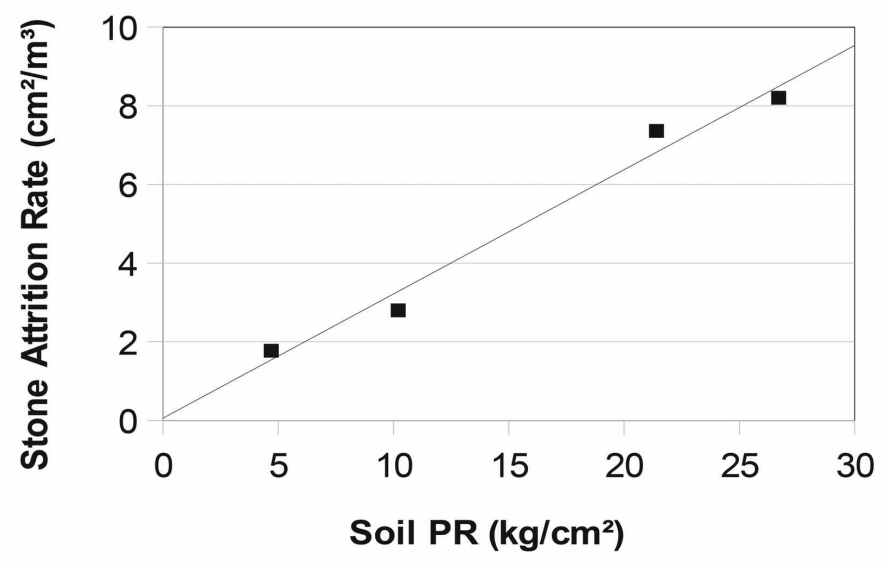

Figure 6. Stone attrition rate as predicted by soil penetration resistance values (PR), with a PR range of $4.7-26.7 \mathrm{~kg} / \mathrm{cm}^{2}$. Black squares along the trend lines indicate results of experiments conducted in Fields IV-VII. Stone attrition rate = $.0494806+.3161917 * \operatorname{PR}\left(r^{2}=.98, p=.011, n=4\right)$.

posed by natural bone morphology, the maximum length of earth-working implements produced from cattle scapulae would be about $23 \mathrm{~cm}$, an estimate based on measurements of 59 modern specimens. We assume prehistoric water buffalo scapulae were similar in size. According to both archaeological and experimental observations, scapular implements shorter than $13 \mathrm{~cm}$ were almost useless for digging. Therefore, a maximum use life of a scapular digging tool would be the amount of work that caused it to wear down a length of $10 \mathrm{~cm}$ from the working edge. Taking implement \#6020 for example, a length of roughly $10 \mathrm{~cm}$ from the working edge covers an area of approximately $120 \mathrm{~cm}^{2}$. Estimates of the use lives of scapular digging tools and their stone counterparts of the same size are listed in Table 6; these calculations assume that material is lost only through use wear.

Bone and stone shovels are both extremely durable in Fields II and III, with soft soils. Although stone appears to be more durable than bone in these two fields, this is probably because the PR values of the experimental plots were slightly lower when stone was used (Table 3; Figure 5). These results suggest that there may not be consistent raw material preference when very soft and fine-grained soils were encountered.

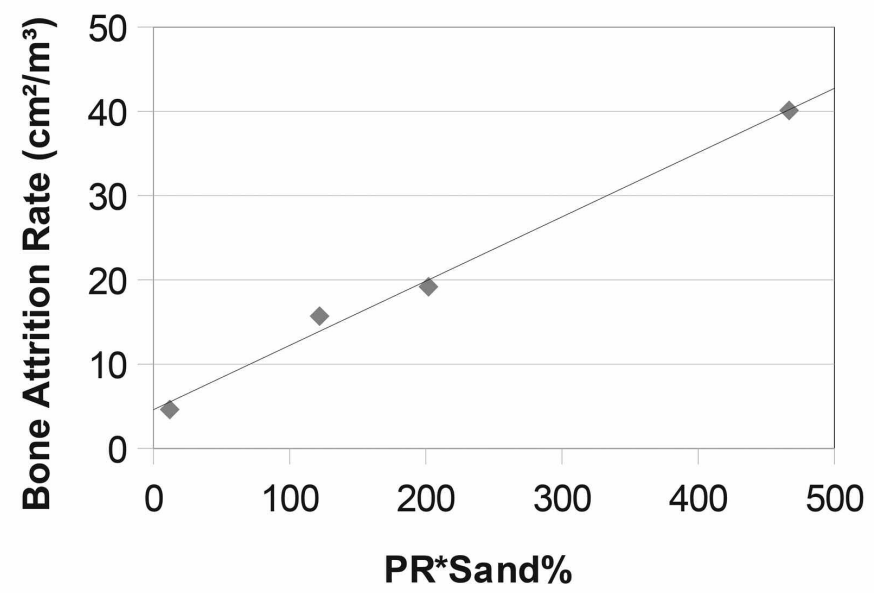

Figure 7. Bone attrition rate as predicted by soil penetration resistance values (PR) and percentage of sand, with a PR range of 4.6-26.1 kg/ $\mathrm{cm}^{2}$. Gray squares along the trend lines indicate results of experiments conducted in Fields IV-VII. Bone attrition rate $=4.409238+.0795057 * \mathrm{PR} *$ Sand $\left(r^{2}=.99, p=.0046, n=4\right)$. 
Table 6. Spade Use-lives, Measured as Volume of Soil $\left(\mathrm{m}^{3}\right)$ Removed.

\begin{tabular}{lcccccc}
\hline & Field II & Field III & Field IV & Field V & Field VI & \multicolumn{1}{c}{ Field VII } \\
\hline Scapula & $4,885.83$ & $1,507.14$ & 26.05 & 6.26 & 7.65 & 2.99 \\
Dolomite & $9,039.79$ & $2,939.97$ & 67.65 & $<43.14^{\mathrm{a}}$ & 16.31 & 14.63 \\
\hline
\end{tabular}

${ }^{a}$ A value of $43.14 \mathrm{~m}^{3}$ over-estimated a dolomite implement's use-life due to an under-estimation of dolomite's attrition rate (see Table 5 and relevant discussion earlier in this article).

Use lives of stone and bone shovels decreased dramatically when dealing with soils in Fields IV-VI and became extremely short in Field VII. Scapulae would probably not be adopted to penetrate ground as compact as that in Fields IVVII. In addition to a longer use life, stone implements were also free from dimensional constraints when proper lithic raw materials were available, so they could be made relatively larger with little additional effort and last even longer.

Our findings regarding differences in performance characteristics relevant to raw material choices between scapulae and dolomite may represent reasonable differentiation between bone and stone in general. However, we are aware that lithic attrition rates vary and that our findings should be adjusted accordingly when applied to specific situations.

\section{Discussion: The Adoption of Bone and Stone Spades and Potential Economic and Social Outcomes}

\section{Predicting Raw Material Preference for Earth- working Implements Based on Soil Properties in the Neolithic Lower Yangzi Basin}

Our experimental results demonstrate that bone implements provided marginally greater time and energy efficiency than stone implements only when soil was extremely soft ( $P R<1 \mathrm{~kg} / \mathrm{cm}^{2}$ ). However, the difference may not have been pronounced enough to lead to a consistent raw material choice. Bone and stone implements function equally efficiently in terms of time and energy costs in soils with PR values of $1-4.7 \mathrm{~kg} / \mathrm{cm}^{2}$, although attrition rates of bone become higher than stone in part of this PR range, beginning somewhere between $3-4.7 \mathrm{~kg} / \mathrm{cm}^{2}$. When soil PR values exceed $4.7 \mathrm{~kg} / \mathrm{cm}^{2}$, stone implements show significantly better efficiency and durability than bone, although for PR values just slightly above the threshold, the difference in efficiency might be too subtle for tool users to perceive. The differences in time and energy efficiency between stone and bone implements may not be noticed before soil PR values exceed $8 \mathrm{~kg} / \mathrm{cm}^{2}$. In soils with PR values higher than $8 \mathrm{~kg} / \mathrm{cm}^{2}$, bone implements simply cannot compete with stone.

Imperceptible or easily overlooked differences in tools' digging efficiency and durability in soils with PR values lower than $8 \mathrm{~kg} / \mathrm{cm}^{2}$ opened up a wider range of technological options to the actors. When soils were this soft, Neolithic populations would have been more likely to consider other performance characteristics that produced direct benefits when choosing raw materials (bone, stone, or both) (Xie 2014).

Results from on-site measurements at Maoshan show that the PR values of the Xiashu Loess and anthropogenic deposits from the Majiabang to Liangzhu periods formed on top of it are higher than $10 \mathrm{~kg} / \mathrm{cm}^{2}$ even when soils are extremely wet (Figure 8). This value exceeds the PR threshold of $8 \mathrm{~kg} / \mathrm{cm}^{2}$ where the greater effectiveness of stone spades becomes apparent, and could fully explain why the Majiabang people consistently chose to use them. In contrast, soil PR values of wetland sediments and superimposed anthropogenic deposits measured at Tianluoshan, the Hemudu site, range from nearly 1 to $45 \mathrm{~kg} / \mathrm{cm}^{2}$ (Figure 8), depending on the moisture levels. This range covers both the PR zone in which there should have been little difference in functionality between the two materials and the zone in which users could discern functional shortcomings in bone spades. Even though PR of wetland sediments and superimposed deposits could be reduced through humidification to the point where bone functioned well, soil softness of wetland sediments still could not have led to a consistent choice of bone over stone. The first author will discuss in a separate paper why Hemudu populations adopted scapular spades and used them for 


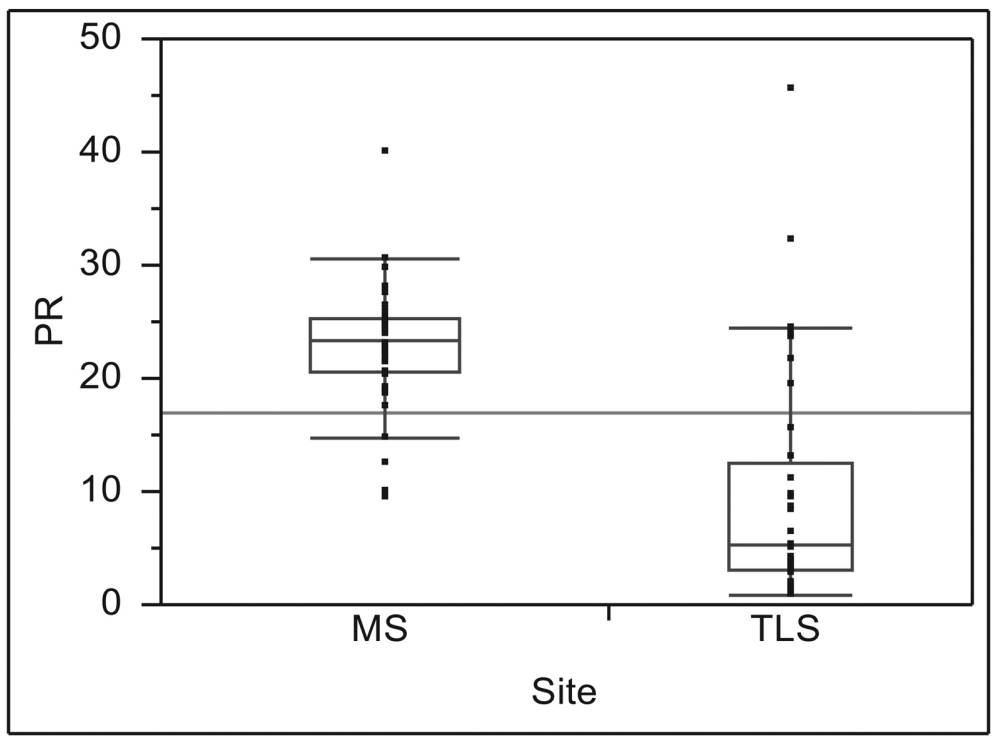

Figure 8. Soil penetration resistance values (PR) in archaeological contexts: the Xiashu Loess and superimposed anthropogenic deposits measured at Maoshan (left), in 44 slots with 10 measurements each and the wetland sediments and superimposed anthropogenic deposits in the Tianluoshan habitation zone (right), in 36 slots with 10 measurements each.

almost a millennium; in this paper, we wish to explore how the choice of earth-working implement would have generated unexpected outcomes that led societies in divergent directions.

\section{Choice of Earth-working Implement and Scales of Landscape Modification}

Choices of earth-working implements affected the feasibility of different forms of land use. It would have been impossible to claim the Xiashu Loessland working with bone spades. The most direct influence of bone spade used by the $\mathrm{Ne}$ olithic Hemudu people was that they became essentially marooned on the margins of the wetlands with small villages and low-level rice production for an extended period.

When the Tianluoshan and Hemudu sites were initially occupied, habitation and rice cultivation were both localized on freshwater paleo-coastal sediments comprised of only .03 percent sand. Anthropogenic sediments built up on the original coastal deposits included an increasingly larger sand fraction over time. Dealing with either the initial coastal deposits or anthropogenic sediments, scapular implements may have fulfilled all functional needs of earthwork in the occupation zones of Hemudu cultural sites. For example, when pen- etrating ground that was close to saturated (with a PR value of $5.5 \mathrm{~kg} / \mathrm{cm}^{2}$ ) in the habitation zone of Tianluoshan, a bone spade would have been able to loosen $8.6 \mathrm{~m}^{3}$ of soil (Supplemental Note 10) within 6.2 hours (Supplemental Note 11). This amount of soil equals to the volume of 20 medium size wet-storage pits discovered at Tianluoshan, and is more than the amount of soil $\left(6.8 \mathrm{~m}^{3}\right)$ removed to create the 20 pits (each $.5-.8 \mathrm{~m}$ wide, .6-1 $\mathrm{m}$ deep) needed for the foundation poles of a medium size $\left(200 \mathrm{~m}^{2}\right)$ pile-dwelling house. To complete the same task when soil PR was 10 $\mathrm{kg} / \mathrm{cm}^{2}$ would have exhausted 1.6 scapular tools and taken 11.9 hours. For structures with small dimensions in the residential area, wetting the soil was practical and ground PR could thus be managed as needed. Therefore, the scapular implements might have been satisfactory for the daily use of workers taking care of the needs of a family. The ease of earth working in the wetlands thus encouraged the formation of a wetland habitation tradition and the choice of scapular digging tools. However, this would have limited the options for expanding villages because (1) the area suitable for habitation was confined to the margins of wetlands, and (2) there was a limited supply of scapulae from hunted herds to be crafted into tools, as 
evidenced by the exhaustion of scapula supply from food refuse and use of less suitable scapulae from other sources (Xie 2014).

The shortcomings of bone spades for largescale land modification become clearer when we consider implement consumption in rice cultivation at Tianluoshan. For example, when soil PR was $3 \mathrm{~kg} / \mathrm{cm}^{2}$, completing tillage in the 6.3 ha of early Hemudu rice fields would have required only five bone spades (Supplemental Note 12). In contrast, if soil PR increased to $4.5 \mathrm{~kg} / \mathrm{cm}^{2}$, more than 200 bone spades to accomplish this task (Supplemental Note 13). To complete tillage in these rice fields with bone spades, it would have cost 30 persons, the maximum population the annual yields of these rice fields could have supported (Zheng et al. 2009), about 21 days when soil PR was $3 \mathrm{~kg} / \mathrm{cm}^{2}$ or 26 days at $4.5 \mathrm{~kg} / \mathrm{cm}^{2}$ (Supplemental Note 14). Time consumption does not seem to be an issue here, but the difference in tool consumption is striking. This implies that, in order for the bone spades to adequately support tillage of the scale that the early Hemudu populations carried out on the wetlands, those tasks had to be undertaken only when the ground was soft. Because the early Hemudu communities lacked water management techniques, decisions about where and how much area to cultivate for rice would have been based on natural wetland conditions. The technical constraints of bone spades may partially explain why rice agriculture never became intensified on the Ningshao Plain even though the Kuahuqiao and Hemudu societies practiced wetland cultivation over millennia.

To sum up, scapular spades must have fulfilled practical needs of individuals and/or families well enough that the actors would not have noticed their relatively short use lives when working soft soils. This allowed bone spade tradition to emerge. However, once the tradition became established, the technology would have influenced strategic thinking about earth-working problems, and would have significantly affected what people expected and planned to get from their surroundings. Even though wetland dwellings and rice cultivation were increasingly untenable on the Ningshao Plain during the Hemudu cultural period, the bone spade tradition and associated landuse strategies did not change until both environmental and cultural influences became very strong, perhaps not even until after colonization by the neighboring Majiabang people. This suggests that technological constraints had influence beyond merely technical issues.

In contrast to Hemudu, early adoption of stone spades by the Majiabang populations allowed them to settle on harder soil substrates and to situate their habitation and rice production more flexibly. With stone spades, they were able to create small artificial rice fields on the hillsides in Xiashu Loess. This would have not only achieved the implicit aim of ensuring productivity through tight control of water levels, but also brought out the unexpected outcome of speeding up fixation of domestication alleles because of the separation of cultivated from wild rice populations (Fuller and Qin 2009). Based on this factor, full-fledged rice agriculture developed sooner than may have otherwise been the case.

The adoption of stone spades also facilitated large-scale landscape modification in pre-metal periods. For example, the movement of the $1,380,000 \mathrm{~m}^{3}$ soil needed to construct the Liangzhu town walls would have required 200 persons approximately 15.6 years to accomplish (Supplemental Note 15). The soil procurement alone also would have required about 82,635 stone spades of similar durability and sizes to our experimental stone implements when the $\mathrm{Xi}$ ashu Loess was at the lowest PR value possible, $22.6 \mathrm{~kg} / \mathrm{cm}^{2}$ (Supplemental Note 16). Such a large supply of implements could have been acquired only if they were crafted from stone, a raw material that was relatively abundant and could be accessed year round, and the production of which could be very rapid when undertaken by highly skilled specialists. However, the whole manufacturing procedure would have also required a significant amount of time and labor. According to experimental results on groundstone spade manufacture, it takes a moderate skilled craftsperson about three hours to complete a yue spade from suitable rock distributed on the northern rim of the Ningshao Plain, excluding stone quarrying time (Xie 2014). Assuming that a highly skilled specialist in prehistory could have produced three stone spades each day, it would have taken 50 craftspeople about 18 months, or five craftspeople daily over a 15.6-year course, to produce the 82,635 stone spades. 
Certainly the estimates above should not be understood as exact. However, they consistently point to the fact that soil procurement for the completion of large-scale earthworks may have required substantial numbers of implements and associated craftspeople in addition to generalized labor. Additional implements and labors would have been needed for other tasks such as acquiring additional architectural materials, transporting materials, construction, and subsistence supply.

\section{Conclusions}

Basic technological choices may resonate widely in a society. Our controlled archaeological experiments generate data needed to estimate the effectiveness of different kinds of digging tools and to estimate labor costs for prehistoric earthwork construction. These findings help explain how soil conditions may have encouraged $\mathrm{Ne}$ olithic people to adopt alternative forms of digging implements in the Lower Yangzi Basin. However, they also imply that early choices about earth-working implements may have affected the processes of intensifying rice agriculture and expanding settlement systems.

The results on tool attrition also create a solid foundation for further investigations of how the recruitment of both generalized and specialized laborers, the organization of craft production, and the relevant logistics for large-scale earthworks may have paralleled the concentrations of political power in prehistory. The results show that prehistoric earthen structures may have demanded significant specialized work from craftspeople that provided fundamental technical support.

We are aware that this is just part of the story. Many other factors, natural as well as social, would have also contributed to the emergence of trajectories toward social and economic complexity. This research provides a perspective that has been largely ignored to help complete the picture.

Acknowledgments. This research was funded by a Henry R. Luce Foundation Dissertation Fellowship/American Council of Learned Societies grant (\#9431 011804 01-7301) awarded to the first author and by the University of Arizona Je Tsongkhapa Endowment for Central and Inner Asian Archaeology. We thank Dean Billheimer and David Raichlen for suggestions on experimental design; Jeffery Homburg and Vance Holliday for sharing thoughts on relevant soil properties; Jill Onken, Amy Schott, Guoliang Lei, and Qian Zhao for assistance with soil property analysis; Weijin Huang, Zhaobing Zhong, Xiaoguang Ma, and Haowei Wo for assistance with digging experiments; 33 local farmers who worked at the sites of Maoshan and Tianluoshan for their invaluable technical and labor support of our archaeological experiments; Randy Haas and Shane Miller for valuable discussions in the initial stages of our writing process; Michael Schiffer, Mary Stiner, Jenny Adams, Xingcan Chen, and Meg Trowbridge for insightful inputs on earlier drafts; Vicki Stefani and Leslie Dupont for polishing our manuscript; Esther Echenique for the Spanish abstract; and Alison Dias for improving the quality of the figures. We are also grateful to Gideon Shelach and three anonymous reviewers for helpful comments on the manuscript.

Supplemental Materials. Supplemental materials are linked to the online version of this paper, which is accessible via the SAA member login at www.saa.org/members-login. Supplemental Notes 1-16 and Supplemental Tables 1 and 2.

\section{References Cited}

Abrams, Elliot Marc

1984 Systems of Labor Organization in Late Classic Copán, Honduras: The Energetics of Construction. Ph.D. Dissertation, Department of Anthropology, Pennsylvania State University, Pennsylvania.

1987 Economic Specialization and Construction Personnel in Classic Period Copán, Honduras. American Antiquity 52:485-499.

1994 How the Maya Built Their World: Energetics and Ancient Architecture. University of Texas Press, Austin. Abrams, Elliot M., and Thomas W. Bolland

1999 Architectural Energetics, Ancient Monuments, and Operations Management. Journal of Archaeological Method and Theory 6(4):263-291.

Arco, Lee J., and Elliot M. Abrams

2006 An Essay on Energetics: The Construction of the Aztec Chinampa System. Antiquity 80:906-918.

Ashbee, Paul, and Ian W. Cornwall

1961 An Experiment in Field Archaeology. Antiquity 35:129-134.

Atkinson, R. J. C.

1961 Neolithic Engineering. Antiquity 35:292-299.

Baker, E. C.

1936 A Wooden Hoe from Majita Peninsula, Victoria Nyanza. Man 36:144.

Best, Elsdon

1976 Maori Agriculture: The Cultivated Food Plants of the Natives of New Zealand, with Some Account of Native Methods of Agriculture, its Ritual and Origin Myths. A. R. Shearer, Government Printer, Wellington, New Zealand. Bengough, A. G., and C. E. Mullins

1991 Penetrometer Resistance, Root Penetration Resistance and Root Elongation Rate in Two Sandy Loam Soils. Plant and Soil 131:59-66.

Cobb, Charles R.

2000 From Quarry to Cornfield: The Political Economy of Mississippian Hoe Production. University of Alabama Press, Tuscaloosa.

Cunnar, Geoffrey Eugene

2007 The Production and Use of Stone Tools at the Longshan Period Site of Liangchengzhen, China. Ph.D. Dissertation, Department of Anthropology, Yale University, New Haven. 
Curwen, E. Cecil

1926 On the Use of Scapulae as Shovels. Sussex Archaeological Collection 67:139-145.

Clark, J. Desmond

1959 The Prehistory of Southern Africa. Penguin Books Ltd., Harmondsworth, U.K.

Dawson, R. J., S. Shewchuk, and J. E. Pritchard

1982 Selection and Use of Hardfacing Alloys. Welding Journal 61(11):15-23.

Ding, Pin

1999 A Preliminary Discussion of the Relationships between the Late Neolithic Cultures on the Northern and Southern Margins of the Qiantangjiang River. In Festschrift in Honor of Zhejiang Provincial Institute of Cultural Heritage and Archaeology's 20th Anniversary, edited by ZPICHA, pp. 49-58. Xiling Press, Hangzhou, China.

Ding, Pin, Yunfei Zheng, Xugao Chen, Zhaobing Zhong, and Ningyuan Wang

2010 The Maoshan Site at Linping, Yuhang, Zhejiang. China Cultural Relics News March 12. Beijing.

Ding, Pin, Ye Zhao, Yunfei Zheng, Wenbao Lu, Zhaobing Zhong, and Xugao Chen

2011 The Most Important Discovery of the Second and Third Excavation Seasons at the Prehistoric Maoshan Settlement in Yuhang, Zhejiang. China Cultural Relics News December 30. Beijing.

Ding, Jinlong

2011 Rice Fields and Rice Agriculture during the Majiabang Cultural Period. In The Origin of the Jiangnan Culture (Vol. I), edited by ZPICHA. Institute of Archaeology in the Nanjing Museum, Jiaxing Municipal Bureau of Culture, Radio, TV, Press and Publication, and Jiaxing Municipal Cultural Heritage Bureau et al., pp. 162-175. China Photography Publishing House, Beijing.

Erasmus, Charles J.

1965 Monument Building: Some Field Experiments. Southwestern Journal of Anthropology 21(4):277-301.

Evans, J. G., and Susan Limbrey

1974 The Experimental Earthwork on Modern Bog, Wareham, Dorset, England: 1963 to 1972. Proceedings of the Prehistoric Society 40:170-202.

Fuller, Dorian Q., and Ling Qin

2009 Water Management and Labour in the Origins and Dispersal of Asian Rice. World Archaeology 41(1):88111.

Fuller, Dorian Q., Emma Harvey, and Ling Qin

2007 Presumed Domestication? Evidence for Wild Rice Cultivation and Domestication in the Fifth Millennium BC of the Lower Yangtze Region. Antiquity 81:316-331.

Gillette, Halbert Powers

1920 Earthwork and Its Cost: A Handbook of Excavation. $3^{\text {rd }}$ ed. McGraw-Hill, New York.

Griffitts, Janet Lynn

2006 Bone Tools and Technological Choice: Change and Stability on the Northern Plains. Ph.D. Dissertation, Department of Anthropology, University of Arizona, Tucson.

Gardner, Walter H.

1986 Water Content. In Methods of Soil Analysis, Part I. Physical and Mineralogical Methods. Agronomy Monograph No. 9, $2^{\text {nd }}$ ed., pp. 493-544. American Society of Agronomy and Soil Science Society of America, Madison.

Hard, Robert Jose J. Zapata, Bruce K. Moses, John R. Roney 1999 Terrace Construction in Northern Chihuahua, Mexico: 1150 B.C. and Modern Experiments. Journal of Field Archaeology 26(2):129-146.
Hammerstedt, Scott William

2005 Mississippian Construction, Labor, and Social Organization in Western Kentucky. Ph.D. Dissertation, Department of Anthropology, Pennsylvania State University, State College.

Hemudu Project Committee (HPC)

1999 Twenty Years of Recognition and Investigation of the Hemudu Culture. In Festschrift in Honor of the Zhejiang Provincial Institute of Cultural Heritage and Archaeology's 20th Anniversary(1979-1999), edited by ZPIACH, pp. 1-16. Xiling Press, Hangzhou, China.

Huang, Weijin

1996 Rethinking the Hemudu Bone si. Cultural Relics (1):61-65

Institute of Archaeology, Chinese Academy of Social Sciences 2010 Chinese Archaeology: Neolithic. China Social Science Press, Beijing.

Jiang, Leping

1999 The Burials at Tashan Lower Layers and the Tashan Culture. Southeast Culture (6):26-35.

2006 Discoveries and Thoughts on the Neolithic Sites in the Puyang River Drainage. In Selected Essays of the Zhejiang Province Institute of Cultural Heritage and Archaeology VIII, edited by ZPICHA, pp. 439-461. Science Press, Beijing.

Kirch, P. V., J. Coil, A. S. Hartshorn, M. Jeraj, P.M. Vitousek, and O.A. Chadwick

2005 Intensive Dryland Farming on the Leeward Slopes of Haleakala, Maui, Hawaiian Islands: Archaeological, Archaeobotanical, and Geochemical Perspectives. World Archaeology 37(2):240-258.

Liu, Li, GyoungAh Lee, Leping Jiang, and Juzhong Zhang

2007 Evidence for the Early Beginning (c. $9000 \mathrm{cal}$. BP) of Rice Domestication in China: A Response. The Holocene 17:1059-1068.

Liu, Li, and Xingcan Chen

2012 The Archaeology of China: From the Late Paleolithic to the Early Bronze Age. Cambridge University Press, New York.

Luojiajiao Archaeological Team

1981 Excavation Report on the Luojiajiao Site, Tongxiang. In Collected Essays of the Zhejiang Province Institute of Cultural Heritage and Archaeology, edited by ZPICHA, pp. 1-56. Cultural Relics Publishing House, Beijing.

Martino, Daniel L., and Carl F. Shaykewich

1994 Root Penetration Profiles of Wheat and Barley as Affected by Soil Penetration Resistance in Field Conditions. Canadian Journal of Soil Science 74:193-200.

McAnany, Patricia A.

1992 Agricultural Tasks and Tools Patterns of Stone Tool Discard near Prehistoric Maya Residences Bordering Pulltrouser Swamp, Belize, In Gardens of Prehistory: The Archaeology of Settlement Agriculture in Greater Mesoamerica, edited by T. W. Killion, pp. 184-213. University of Alabama Press, Tuscaloosa.

Milner, George R.

1998 The Cahokia Chiefdom: The Archaeology of a Mississippian Society. Smithsonian Institution Press, Washington, D.C.

Milner, George R., Scott W. Hammerstedt, and Kirk D. French 2010 Chert Hoes as Digging Tools. Antiquity 84:103-113.

Muller, Jon

1997 Mississippian Political Economy. Plenum, New York.

Nakajima, T., M. Nakajima, T. Mizuno, G.-P. Sun, S.-P. He, and H.-Z. Liu

2012 On the Pharyngeal Tooth Remains of Crucian and Common Carp from the Neolithic Tianluoshan site, 
Zhejiang Province, China, with Remarks on the Relationships between Freshwater Fishing and Rice Cultivation in the Neolithic Age. International Journal of Osteoarchaeology 22:294-304.

Pan, Yan

2011 Resource Production from 10,000 to 6,000 BP on the Yangzi Delta and Qiantangjiang Drainage: Paleoethnobotanical and Human Ecological Studies. Ph.D. Dissertation, School of Archaeology and Museology, Fudan University, Shanghai.

\section{Qin, Ling}

2013 The Liangzhu Culture. In A Companion to Chinese Archaeology, edited by A. P. Underhill, pp. 574-596. Blackwell, Sussex, U.K.

Sinnett, D., G. Morgan, M. Williams, and T. Hutchings

2008 Soil Penetration Resistance and Tree Root Development. Soil Use and Management 24(3):273-280.

Shelach, Gideon

2013 Collapse or Transformation? Anthropological and Archaeological Perspectives on the Fall of Qin. In Birth of an Empire: The State of Qin Revisited, edited by Y. Pines, L. V. Falkenhausen, G. Shelach, and R. Yates, pp. 113-138. University of California Press, Berkeley.

Sun, Guoping

2013 Recent Research on the Hemudu Culture and the Tianluoshan Site. In A Companion to Chinese Archaeology, edited by A. P. Underhill, pp. 555-573. Blackwell, Sussex, U.K.

Sun, Guoping, and Weijin Huang

2000 A Report on the Excavation at Xiangjiashan, Yuyao County. Prehistoric Studies, edited by the Xi'an Banpo Museum, pp. 385-427. Sanqin Press, Xi'an, China.

Wang, Haiming

2009 The Neolithic Site of Siqianshan, Yangxunqiao, Shaoxing City: The Discovery of a Stone Fence of the Majiabang Culture. In A New Era of Zhejiang Archaeology, edited by ZPICHA, pp. 36-37. Science Press, Beijing.

Webb, John, Anne Ford, and Justin Gorton

2007 Influences on Selection of Lithic Raw Material Sources at Huizui, a Neolithic/Early Bronze Age Site in Northern China. Indo-pacific Prehistory Association Bulletin 27:76-86.

Webster, David, and Jennifer Kirker

1995 Too Many Maya, Too Few Buildings: Investigating Construction Potential at Copán, Honduras. Journal of Anthropological Research 51:363-387.

Wilson, Gilbert Livingstone

1917 Agriculture of the Hidatsa Indians: An Indian Interpretation. Studies in Social Sciences 9, Bulletin of the University of Minnesota, Minneapolis.

Xie, Liye

2014 Early to Middle Holocene Earth-working Implements and Neolithic Land-use Strategies on the Ningshao Plain, China. Ph.D. Dissertation, School of Anthropology, University of Arizona, Tucson.

Yang, Yongzhao, Fuchun Li, Zhihong Cao, Meinong Wang, Zhangdong Jin, Jingyu Dai, and Wei Ran

2007 Identifying Paleosol Parent Materials at the Chuodun Site in Kunshan Based on Soil Particle Size. Chinese Journal of Soil Science 38(1):1-5.

Yu, Weijie.

1993The Acquisition and Maintenance of the Hemudu Rice Field. Ancient and Modern Agriculture (4):36-43.

Zheng, Jianming

2008 Environment, Adaptation, and Social Complexity: Prehistoric Cultural Changes in the Lake Taihu Area and the Ningshao Plain. Shanghai People Press, Shanghai, China.

Zheng, Leping, Xuefeng Hu, and Xiaomin Fang

2002 A Review of the Study of the Origin of the Xiashu Loess in the Middle and Lower Yangzi Regions. Bulletin of Mineralogy, Petrology and Geochemistry 21(1):5457.

Zheng, Yunfei, Guoping Sun, Ling Qin, Chunhai Li, Xiaohong Wu, and Xugao Chen

2009 Rice Fields and Modes of Rice Cultivation between 5000 to 2500 BC in East China. Journal of Archaeological Science 36:2609-2616.

Zheng, YunFei, GuoPing Sun, and XueGao Chen

2012 Response of Rice Cultivation to Fluctuating Sea Level during the Mid-Holocene. Chinese Science Bulletin 57(4):370-378.

Zhejiang Provincial Institute of Cultural Heritage and Archaeology (ZPICHA)

1997 The Neolithic Site at Kuahuqiao, Xiaoshan. In Proceedings of the Zhejiang Provincial Institute of Cultural Relics and Archaeology II:6-21. Hangzhou, China.

2002 A Brief Excavation Report of the Xiaodongmen Site, Cicheng, Ningbo. Southeastern Culture (9):17-30.

2003 Heтudu: A Neolithic Site. Cultural Relics Publishing House, Beijing.

2005 Excavation Report on the Nanhebang Songze Culture Site. Cultural Relics Publishing House, Beijing.

2008 Excavation of the Liangzhu Ancient City Site in Yuhang County, Hangzhou, in 2006-2007. Archaeology (7):3-10.

2011 A Summary of Archaeological Field and Lab Work at Tianluoshan during the First Working Stage (years 2004-2008). In Integrated Studies on the Natural Remains from Tianluoshan, edited by the Center for the Study of Chinese Archaeology, Peking University and ZPICHA, pp. 7-39. Cultural Relics Publishing House, Beijing.

ZPICHA and XM (Xiaoshan Museum)

2004 Kuahuqiao. Cultural Relics Publishing House, Beijing.

ZPICHA and the Yuyao Municipal Administration of Cultural Relics

1997 Excavation Report of Liangzhu Altar-Cemetery at Huiguanshan in Yuhang, Zhejiang. In Collected Essays of the Zhejiang Province Institute of Cultural Heritage and Archaeology II, edited by ZPICHA, pp. 74-93. Changzheng Press, Beijing.

Zhao, Ye

2001 Excavation of the Mojiaoshan Site 1992-1993 at Yuhang. Cultural Relics (12):4-19.

2007 The Vanished Capital of an Ancient Chiefdom: The Liangzhu Site. Zhejiang Photography Publishing House, Hangzhou, China.

Zou, Houben, Jianxiang Gu, Minchang Li, Linghua Tang, Jinlong Ding, and Qinde Yao

2000 The Majiabang Culture Rice Fields at Caoxieshan, Jiangsu. In The Origins of Rice Agriculture, Pottery and Cities, edited by W. Yan and Y. Yoshinori, pp. 97-113. Cultural Relics Publishing House, Beijing.

Submitted November 21, 2013; Revised April 16, 2014;

Revised August 6, 2014; Accepted October 27, 2014. 